\title{
Cognitive therapy of psychosis in clinical practice
}

\author{
Nagy Riad Bishay
}

Aims and method The study aimed at developing a brief cognitive intervention suitable for everyday management of psychotic patients. A brief cognitive therapy package was developed and tested on different patients with psychosis.

Results in conjunction with medication, a brief cognitive intervention helped some patients with psychosis at different stages of the illness.

Clinical implications This encouraging report justifies more detailed studies.

During the last two decades, cognitive therapy has been established as an effective treatment in many psychiatric illnesses. The last few years have seen the emergence of brief interventions for use in everyday practice.

This article describes a brief cognitive intervention drawn from Beck's model of cognitive psychopathology and therapy package (Beck et al, 1979) to help psychiatrists in their daily work.

\section{Example of the intervention}

During his first two years practising cognitive therapy, the author was asked to see a 28-yearold woman who had had a caesarean section performed 10 days earlier. She had already been prescribed dothiepin two days previously as she was diagnosed as suffering from puerperal depression. That morning she revealed paranoid symptoms, hence the assessment.

During the interview she became apprehensive and said, "The nurses must be right, I must be going mad, I feel things nobody else does". Further questioning revealed that she felt cold. As the therapist had the same experience and pointed to an open window, she calmed down. The therapist seized the opportunity to introduce the principle: changing the way we think changes the way we feel. The therapist continued to deal with "I smell things the nurses don't. I have harmed my son and husband". Through reviewing the work of Tarrier, Garrety, Turkington, Kingdon, Birchwood, Haddock, Fowler, Kuipers, Bentall and others (Haddock \& Slade, 1996) it was possible to apply Beck's model of cognitive psychopathology as follows:
The rules: Infidelity will cause fatal venereal disease to be passed on to husband and children. Only bad people do it.

The early experience: She was unfaithful once two months after the marriage, two years earlier.

Dormant maladaptive schemata: She caught a fatal sexually transmitted disease and passed it on to her husband and in the future would pass it on to her children. She believed herself to be a bad woman and expected people to know this.

Precipitating event: The birth of her child resulted in activation of the maladaptive schemata. Subsequently any stimulus came to be interpreted as evidence that the fears had come true; the child does not move, therefore he is dead; she hears a voice, the voice says "she is smelly", therefore people know about what she has done. In-laws offer help; therefore they know she is a bad wife and mother. The automatic thoughts are a brief statement of the conclusion not the condition. They are accepted without questioning. They are not easily accessible. Salkovskis (1985) suggested that obsessive thoughts are like automatic thoughts but accessible. The delusional beliefs are equally accessible but strongly held in spite of the evidence to the contrary. Equally the delusional and hallucinatory experiences are the conclusions not the condition, so they can be regarded as automatic thoughts: "My son is dead", "My husband is ill, dying", "I am a bad mother". "They say I cannot look after my baby". The only difference is that anxious patients do not say. "I am dead". They say. "I'll die".

The main cognitive schemata were: (a) The dangers (fear) of the consequences of earlier experiences; and (b) Self-blame (guilt) about earlier experiences.

The main strategy was to deal with the rules that contributed to the development of the maladaptive schemata. The main technique was guided discovery; the skills are illustrated elsewhere (Bishay \& Goldberg, 1985). The woman responded to the combination of drugs and rehearsal of rational statement. She was thought 
fit to look after her child by the obstetricians treating her, who discharged her three days later. Follow-up in the out-patient department confirmed the continued improvement. As the therapist believed that reasoning cannot change delusional beliefs the diagnosis was changed to a neurosis and the medication discontinued. This resulted in a recurrence a few weeks later. The reinstatement of the medication made it easier to continue with the cognitive restructuring and the patient's use of self-statements resulted in improvement. Sadly the patient's cooperation with medication was limited and she kept experiencing recurrences.

\section{Implications}

This showed that psychosis could be treated by cognitive therapy alongside medication. Unfortunately, not all people responded to such an approach even when seen a few days after the onset of the illness. Thorough observation concluded that our patients were suffering from psychotic depression, psychogenic psychosis and some forms of schizophrenia (where environmental factors play a role i.e. environmental and not neurodevelopmental schizophrenia). The psychopathology was self-blame, danger, anger or any combination.

Does the duration of the illness matter?

Some people treated for several years responded to the intervention once seen by the therapist.

\section{Can one stop medication?}

The answer would be no for the time being, for medico-legal reasons. Research will have to establish the period for medication. Some people stopped their medication and seemed to be doing well.

\section{Can one start cognitive therapy before medication?}

It seems that taking the drugs for as short a period of two days was sufficient. Medication taken the same day helped one person to work with the therapist during the session but it was not possible to achieve any lasting effect and the person required hospitalisation later on the same day suffering from a severely excited state. He continued to work with cognitive skills immediately after the control of the acute phase through the use of chemotherapy.

\section{Would the psychiatrist need to spend too much} time?

Generally the initial session is hard work. The involvement of other members of the team can be useful in helping the psychiatrist by emphasising and reinforcing the previously achieved rational statements.

Are the cognitive therapy skills different from those used in non-psychotic people?

Since the first case was thought of as a neurosis the skills are not different. The main difference may be that a good proportion of these people may not be able to apply the skills in different situations and will require the therapist to do the work for quite some time before they learn it.

\section{Can cognitive therapy be useful to other} people?

The integration of cognitive psychopathology and therapy in the repertoire of clinical skills of the clinician can improve people's compliance with medication, dealing with life events, cooperation with rehabilitation programmes and better family understanding.

\section{Cooperation with medication}

Our clinical experience suggests that the main points that need to be addressed are:

(a) The stigma of the illness. Psychiatric illness is an illness that may require drugs to treat it, as do many other illnesses. In other words, it involves chemical changes like those in diabetes, high blood pressure etc. There is nothing wrong with taking medicines, such patients take them for the rest of their lives and in some cases it is necessary for people with psychiatric illnesses to do so.

(b) The balance between advantages and disadvantages of taking the medication. It may offer the opportunity to rebuild one's life, to live in one's own flat or to keep one's child.

\section{Dealing with life events}

(a) The loss of a job. The person should be helped to produce a balance sheet of what would be lost and what gained. More likely than not the person will realise that the pressures of the job and other newcomers being promoted while he is passed over, would make keeping the job a stressful situation. In other words the loss of the job may help the person to gain relief from stresses that may precipitate recurrences and so lead to a happier and healthier life. There may be financial gains, like having a pension and either sickness benefit or another salary.

(b) Loss of dear ones. Normalise grief and comfort believers in the hope of meeting 
again in the next life. Review the financial situation to address the worries about survival, and so on.

Treatment during rehabilitation

This is similar to cooperation with medication, namely the balance sheet of what one would gain versus what one would lose through lack of cooperation. Also, people should take heart from the success achieved with the aid of staff, and build on this independently.

Work with families

Tarrier (1996) described a package for dealing with high expressed emotions in the family but in everyday practice the consultant psychiatrist would need to concentrate on:

(a) Helping the family to accept that their son or daughter is now a disabled person. Accepting this will help them to control their highly expressed emotions.

(b) Helping people to understand family members' intentions. They need to be reassured that their emotional reaction is a result of anxiety and not the family trying to criticise the sufferer. It is important the people do not view the therapist as siding with their families.

(c) Sometimes people do manipulate their relatives against members of the rehabili- tation team. It would be important to point out to the relative the person's manipulative behaviour to help smooth cooperation between all concerned.

\section{Conclusion}

Controlled studies or audit of the effectiveness of these approaches is required.

\section{References}

BECK. A. T., RUSH, A. J., Shaw, B. F., et al (1979) Cognitive Therapy in Depression. New York: Gullford Press.

BishaY, N. R. \& GOLDBERG, D. (1985) Seminars in Behavioural Psychotherapy. $3 \& 4$. Techniques of Cognitive Therapy. London: Tavistock Publications.

HADDOCK. G. \& SLADE, P. D. (1996) Cognitive Behavioural Interventions with Psychotic Disorders. London: Routledge.

SALKovSKIS, P. M. (1985) Obsessional-compulstve problems: a cognitive behavioural analysis. Behaviour Research and Therapy, 23, 271-583.

TARRER, N. (1996) Family interventions and schizophrenia. In Cognitive Behavioural Interventions with Psychotic Disorders (eds G. Haddock \& P. Slade). pp. 213-214. London: Routledge.

Nagy Riad Bishay, Consultant Psychiatrist, Park House, North Manchester General Hospital, Delaunays Road, Crumpsall, Manchester M8 5RB 